\title{
Pediatric inflammatory multisystem syndrome (PIMS) presenting with retropharyngeal phlegmon mimicking Kawasaki disease
}

\author{
Purbasha Gupta $^{1} \cdot$ Prabhas Prasun Giri $^{2} \cdot$ Dipankar Das $^{3} \cdot$ Priyankar Pal $^{4}$ (D) \\ Received: 6 November 2020 / Revised: 1 December 2020 / Accepted: 5 December 2020 / Published online: 13 January 2021 \\ (C) International League of Associations for Rheumatology (ILAR) 2021
}

There have been several recent reports of children presenting with severe multisystem inflammatory syndrome (PIMS) resembling complete or incomplete Kawasaki disease (KD) during COVID19 pandemic. Being a novel disease, limited data is available for its identification and management. We report a child presenting with fever, neck swelling, and generalized edema, who was diagnosed as PIMS. MRI neck showed retropharyngeal phlegmon resembling similar finding in $\mathrm{KD}$.

\section{Presentation}

A 4-year-old boy presented with high fever for 6 days along with a painful neck swelling associated with bilateral nonpurulent conjunctivitis, facial puffiness, and extreme irritability. He had tachycardia, hypotension, S3 gallop, and generalized edema. The neck swelling was extremely painful causing neck stiffness. With a working diagnosis of sepsis and myocarditis empirical broad spectrum, antibiotics were started, but a possibility of KD and PIMS was also considered. Echocardiography showed grade 1 systolic dysfunction, and MRI neck (Fig.1) demonstrated a retropharyngeal fluid collection with soft tissue edema, likely to be a retropharyngeal phlegmon, as described in KD. COVID RT-PCR was negative but COVID IgG was positive.

Priyankar Pal

mailme.priyankar@gmail.com

1 Department of Paediatric Medicine, Institute of Child Health, Kolkata, West Bengal, India

2 Paediatric Intensive Care Unit, Institute of Child Health, Kolkata, West Bengal, India

3 Department of Radiology and In charge of MRI unit, Institute of Child Health, Kolkata, West Bengal, India

4 Department of Paediatric Rheumatology, Institute of Child Health, Kolkata, West Bengal, India
He was treated with IVIg @2 g/kg followed by IV methyl prednisolone @ $5 \mathrm{mg} / \mathrm{kg} /$ day for 3 days. Fever subsided within $48 \mathrm{~h}$ of IVIg, and the inflammatory markers started normalizing (Table 1) on repeat testing after3 days of methylprednisolone. The child was discharged on low-dose aspirin and oral prednisolone $2 \mathrm{mg} / \mathrm{kg}$ /day to be tapered over 15 days, with advice for a follow-up echocardiography after 14 days. The child is doing well at present, and repeat echocardiography is within normal limit.

\section{Discussion}

There has been several case reports of KD presenting with retropharyngeal edema/phlegmon $[1,2]$. This fact that cervical lymphadenopathy in KD can be associated with deeper soft

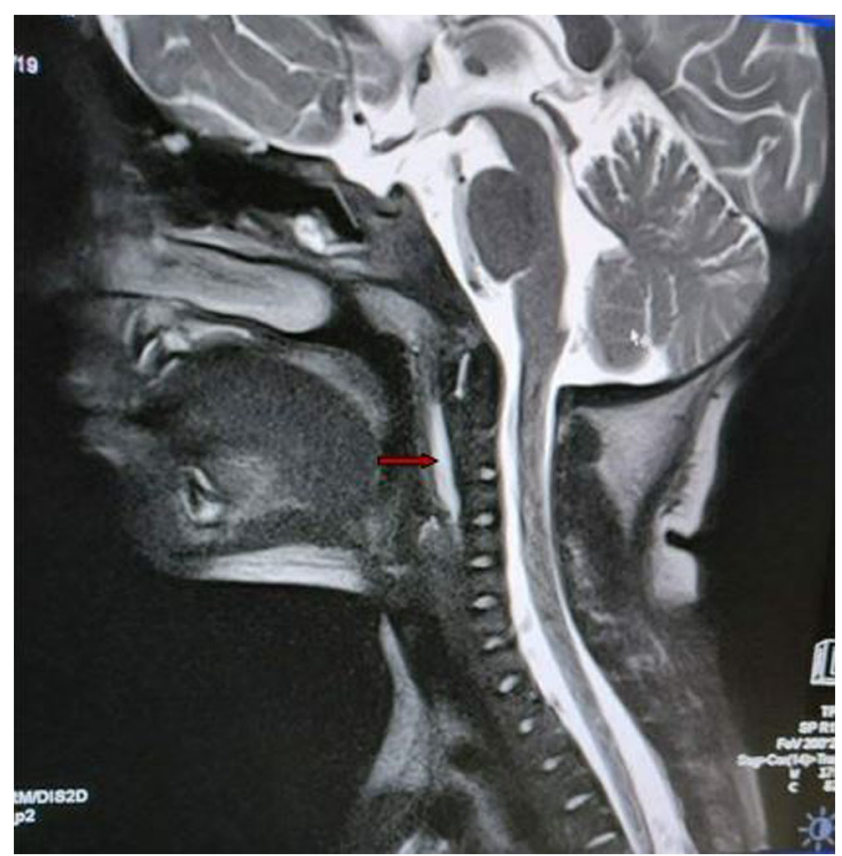

Fig. 1 MRI neck showing linear retropharyngeal fluid collection with soft tissue edema without any compression over the airway 
Table 1 Comparison between the different laboratory markers before and after starting treatment with IVIg and methyl prednisolone, respectively

$\begin{array}{lll}\text { On admission (D1) Day of starting IVIg (D2) } & \begin{array}{l}\text { After } 48 \text { h of IVIg } \\ \text { completion (methyl } \\ \text { prednisolone initiated) }\end{array}\end{array}$

\begin{tabular}{|c|c|c|c|c|c|}
\hline Investigations & Normal range & $22 / 09 / 2020$ & $23 / 09 / 2020$ & $25 / 09 / 2020$ & $29 / 09 / 2020$ \\
\hline Total leucocyte count (/cmm) & $4000-10,000$ & 9600 & 9410 & 9910 & 8420 \\
\hline Differential count $(\%)$ & N 40-60 & N 66 & N 79 & N 66 & N 34 \\
\hline N-neutrophil L-lymphocyte & L $20-40$ & L 29 & L 18 & L 29 & L 58 \\
\hline Hemoglobin(g m\%) & $11-14$ & 9.4 & 10.2 & 9.1 & 10.6 \\
\hline Platelets $(\times 109 / 1)$ & $150-400$ & 218 & 103 & 319 & 617 \\
\hline CRP (mg/l) & $<5$ & 318.3 & 191 & 94.1 & 30 \\
\hline Urea $(\mathrm{mg} / \mathrm{dl})$ & $7-20$ & 18 & 17 & 17 & 18 \\
\hline Creatinine(mg/dl) & $0.3-0.8$ & 0.39 & 0.38 & 0.36 & 0.36 \\
\hline Sodium $(\mathrm{mEq} / \mathrm{l})$ & $135-145$ & 128 & 134 & 137 & 136 \\
\hline Potassium (mEq/l) & $3.5-5$ & 3.2 & 3.5 & 4.4 & 4 \\
\hline $\begin{array}{l}\text { Total Bilirubin (mg/d } \\
\text { 1) }\end{array}$ & $0.1-1.2$ & 0.39 & 0.4 & 0.4 & 0.38 \\
\hline Total protein $(\mathrm{g} / \mathrm{dl})$ & $6-8$ & 4.4 & 6.4 & 6.7 & 7.2 \\
\hline $\operatorname{Albumin}(\mathrm{g} / \mathrm{dl})$ & $3.5-5.5$ & 2.5 & 3.2 & 3.5 & 4 \\
\hline $\operatorname{ALT}(\mathrm{U} / \mathrm{l})$ & $7-50$ & 10 & 12 & 13 & 12 \\
\hline AST (U/l) & $10-40$ & 32 & 34 & 33 & 34 \\
\hline Ferritin (ng/ml) & $<250$ & 570.2 & 340.5 & 198 & 76 \\
\hline Interleukin 6 & $<7 \mathrm{pg} / \mathrm{ml}$ & 91.2 & 57 & 12 & 12 \\
\hline NTpro BNP & $<450 \mathrm{pg} / \mathrm{ml}$ & 29,562 & 12,764 & 5436 & 2917 \\
\hline
\end{tabular}

tissue inflammation leading to non-suppurative edema is being increasingly recognized and has been included as "Other Clinical Finding" in the AHA 2017 Scientific Statement on KD [3].

With the onset of the COVID 19 pandemic, cases presenting with multisystem hyperinflammation (PIMS) resembling atypical KD are being frequently reported globally [4, 5]. Though cervical lymphadenopathy is present as an associated finding in some of these patients, the authors did not come across any description of retropharyngeal edema in the available literature. This child presented with high fever with painful torticollis and had other features of systemic inflammation with myocarditis resembling PIMS. Although there was no history of exposure to COVID, he tested positive for COVID IgG signifying an asymptomatic past infection. He responded very well to IVIg and IV methyl prednisolone with improvement of biochemical parameters and echocardiography findings.

\section{Compliance with ethical standards}

Disclosures None.

Patient consent Obtained. Written consent has been attached.

\section{References}

1. Kanegaye JT, Van Cott E, Tremoulet AH, Salgado A, Shimizu C, Kruk P, Hauschildt J, Sun X, Jain S, Burns JC (2013) Lymph-nodefirst presentation of Kawasaki disease compared with bacterial cervical adenitis and typical Kawasaki disease. J Pediatr 162:12591263. e2. https://doi.org/10.1016/j.jpeds.2012.11.064

2. Kato H, Kanematsu M, Kato Z, Teramoto T, Kondo N, Hoshi H (2012) Computed tomographic findings of Kawasaki disease with cervical lymphadenopathy. J Comput Assist Tomogr 36:138-142. https://doi.org/10.1097/RCT.0b013e31823b4497

3. McCrindle BW, Rowley AH, Newburger JW, Burns JC, Bolger AF, Gewitz $\mathrm{M}$ et al (2017) Diagnosis, treatment, and long-term management of Kawasaki disease: a scientific statement for health professionals from the American Heart Association. Circulation. 135: e92799-e9e999. https://doi.org/10.1161/CIR.0000000000000484

4. Verdoni L, Mazza A, Gervasoni A et al (2020) An outbreak of severe Kawasaki like disease at the Italian epicentre of the SARS-CoV-2 epidemic: an observational cohort study. Lancet. https://doi.org/10. 1016/S0140-6736(20)31103-X

5. Dhanalakshmi K, Venkataraman A, Balasubramanian S, Madhusudan $M$ et al (2020) Epidemiological and clinical profile of pediatric inflammatory multi system syndrome - temporally associated with SARSCOV-2 (PIMS-TS) in Indian children. Indian Pediatr

Publisher's note Springer Nature remains neutral with regard to jurisdictional claims in published maps and institutional affiliations. 